\title{
From Business Agile to Agile Education: a response to change in times of pandemic
}

\section{Luisa-Eugenia Reyes, Elena Fernández-Gascueña, Rocío Usero}

Business Economics, Rey Juan Carlos University, Spain.

\begin{abstract}
The aim of this document is to present a new teaching model in higher education focus on the student. The model develops an iterative and incremental learning system based on the fundamentals of agility and the organization of agile work, improving learning performance and the benefit of students.

This model develops a system based on the Scrum methodology that allows continuous deliveries of value from the student to the teacher, adapted to the learning goals of the educational programs, approaching a cultural, organizational and structural change through the application of methods, Agile practices and dynamics within a framework that encourages innovation and continuous improvement of students.
\end{abstract}

Keywords: Agile; higher education; scrum; innovation learning environments; teaching experience. 


\section{Introduction and Background}

The digital transformation and the increasing complexity of today's environments demand greater flexibility from all organizations that will adapt to an uncertain and increasingly volatile future. The relative effectiveness of current educational management and the demand for new competences for both students and teachers are the engine that must serve as the impetus for the transformation of teaching (Lembo and Vacca, 2012).

The University, due to its researcher character, is a source of novelty and, applying the basis of Agility to education implies formulating a new teaching model which puts the student in the center of the learning process, being quality the main axis thereof, from the beginning to the end of the training.

The objective of the model is a more efficient and effective learning, thus the design of the subjects by the teaching staff has been defined based on the organization of the Scrum work, so that the students develop teamwork skills, the motivation to learn and achieve better academic results (López-Alcarria et al., 2019).

The change means transforming the teacher-focused, individualistic and hierarchical education model through the master class, into a system with a more horizontal structure that allows continuous value delivery in an iterative and incremental way and in which teachers and students form a committed and cohesive team that shares common goals and values (Cathcart, et al., 2014). The team, following the Scrum's style, become a project manager in which the objective of the final product is the learning of the students.

The theoretical foundations of the teaching-learning model take as reference the works of Salza et al., (2019), Stewart et al., (2009); Krehbiel et al., (2017) regarding the application of agile principles related to teamwork, transparency and communication, generating a change in the way that students acquire knowledge. In this way, a new work model is generated in which teachers actively collaborate with students sharing their knowledge, so that they develop certain valuable deliverables that reflect their learning in continuous cycles.

One of the supports of the model is the management of people as a source of agility. It is important to empower and involve students in their learning process to generate a motivating environment that encourages commitment, responsibility, collaboration and confidence, and that reveals the curiosity and creativity that will lead to improved results in the subjects.

The course is developed through a collaborative and cohesive team of students and teachers in a Scrum style, which can become a project manager and in which the objective of the final product is student learning. Student teams are structured and empowered so that they can self-manage their own work. They plan and determine their own activities and track progress. The teacher acquires a role of facilitator determining the assignments of activities, training and advising so that the students can achieve the objectives and overcome the subject. 
Inspection, adaptation and transparency are key tools to achieve continuous improvement. Inspection manifests itself in mechanisms to examine the work that students are doing and especially how they are doing it. And adaptation is what will allow the student team to make decisions and take actions that improve results. There must be a clear communication that ensures that all the changes that are made are transparent, visible, understandable by the team and useful, in such a way that the quality of the results increases.

An incremental approach makes the students' knowledge build from its foundations, progressively, and in detail. The iterative approach means that in the short cycles the students deliver activities or completed tasks, to which already acquired knowledge is added.

\section{Model Design and Methodology}

To implement the model in the classrooms, a Scrum-based model is applied that allows adaptability, flexibility and innovation in any subject, it is even adaptable to adverse situations that require drastic changes in the way the subject is taught. This model is especially important not only in current situations such as pandemic, but in all situations that imply changes in methodologies, forms and tools of work.

The teaching model based on Scrum was implemented in the subjects of Project Management of the degrees in Science, Management and Service Engineering: Business Administration in the Digital Environment as well as in the degree of Architecture of the Rey Juan Carlos University.

The application of the model requires the definition of different roles, being the main ones:

- The Developers are teams of students who must create a plan for the Sprint. This will be developed through practices or tasks that the teacher can establish or leave to the free choice of the teams so that they can adapt their plan orienting it to the objective of the Sprint in a creative way. Student teams are self-managing, that is, they decide internally who does what, when and how. They are responsible for creating a valuable and useful Increment in each Sprint.

- The Scrum Master as teacher is responsible for establishing Scrum by helping students understand the theory and practice of both Scrum and the contents of the subject. The method used was the recording of training pills of the contents of the syllabus and associated deliverables according to the requirements in terms of skills and competencies to be acquired. The teacher should help student teams to focus on creating high-value Increments that meet the definition of Done (that is, the team deliverable demonstrates that knowledge has actually been acquired). The teacher must eliminate the impediments to the progress of the students, guiding and training the students, solving doubts and clearly explaining the objectives so that the students 
understand how far they have to go to achieve a Finished Increment. For this, weekly remote work sessions were carried out through Blackboard Colaborate and Mural with the developers

On the other hand, the events are presented. The main ones are:

- The Sprint, of fixed duration and established by the teacher, determined by the teaching time for each of the lessons. In them the student teams develop certain tasks that comply the Sprint Objective. If Sprints are short, more learning cycles are generated, and the risk of misguided effort is limited to a shorter period of time. Each Sprint is considered a short project that teams have to carry out in collaboration with the teacher. In each of the sprints, a deliverable is finished that allows to place value on new skills and competences regarding the previous sprint.

- The Sprint Planning establishes the work to be done in the Sprint, and is created by the Developers. The teacher explains to the students how the activities or deliverables that finish in the Sprint have to be worthwhile and useful to the Sprint learning goal. Developers plan the work required to create an Increment that meets the Definition of Done. How to do it is at the sole discretion of the student teams. No one else tells them how to convert Product Backlog items into Value Increments, as the teacher is only there to guide. In the sprint planning the develpers will add their own user stories to those of the teacher and stakeholders in order to create the increment. In addition, the teams are given the planning poket cards and they are instructed in the use and analysis of the progress graphs.

- The Daily Scrum is a short meeting that is held between student teams to inspect progress toward the Sprint Goal and adapt the Sprint Backlog as needed. The Scrum Master can attend at any of these meetings if is actively working with student teams or have doubts about the Sprint Goal.

- The Sprint Review has the purpose of inspecting or evaluating the result of the Sprint. The student team present the results of their work to the teacher and the progress towards the final goal of the subject is discussed. What has been achieved by the students is reviewed and together with the teacher it is determined what to do or how to move forward next. During the implementation in the classroom, the teacher has met with all the teams in each of the sprint reviews.

- In the Sprint Retrospective the student team inspects how their last Sprint was with respect to people, interactions, processes, tools, and their Definition of Done. The assumptions that led them astray are identified and their origins explored. Developers must identify the most useful changes to improve their efficiency toward achieving the next Sprint Goal. Templates were provided to the teams to guide the process and structure continuous improvement in the process to instruct the effective use of retrospectives. 
Moreover, the model describes some Scrum artifacts such as:

- The Product Backlog, where student teams must acquire, develop and demonstrate specific iterative knowledge, which at the end of the course will make up in a single document that will contain all the learnings from each Sprint. In this way the Product Backlog is an arranged list of what students need to learn to complete the course. The product backlog at least is defined by the set of competencies and skills necessary to pass the subject defined in the official memory of the degree.

- The Sprint Backlog is formed by the Sprint Objective (why) communicated by the teacher, the Product Backlog elements selected for the Sprint (what) also established by the teacher, and an action plan to deliver, the Increment (how) which is developed by student teams.

- The Increment is a concrete advance towards the total learning that students must have gained at the end of the subject. Each Increment is added to the previous deliverable as continuous evaluation. In this way, little by little, the final project that will demonstrate what the student teams have learned is built.

\section{Result and Conclusions}

\subsection{Result}

To measure the effect of the implementation of the teaching model based on Scrum, we have proceeded to analyze both the results in terms of qualifications and the evaluation rubrics of the teaching staff. First, we address student outcomes. An analysis of the qualifications indicates better results of the students in learning in terms of qualification since in the academic year 2020/2021 in a pandemic situation and with the methodological change, no students abandoned the course or failed compared to the 2019/2020 academic year in which $0.08 \%$ abandoned and $0.04 \%$ suspended. On the other hand, regarding those who obtained "Pass" and "Good" marks, while in the academic year 2019/2020 were $43.47 \%$ and $43.47 \%$ respectively, in the $2020 / 2021$ only $19.63 \%$ passed the subject, being an $84.37 \%$ those who obtained a qualification of "Good".

Second, we undertake a comparative analysis of the students' responses to the teachers' evaluations in the last two years for the subjects being implemented. It is necessary to indicate that the evaluation of the students is from 0 to 5 points for each of the items surveyed. Specifically, regarding the evaluation of the students according to the rubics of the evaluation of the University teaching staff in the last two and that are shown in table 1, it is necessary to state that the professor 1 teaches in online degrees and the professor 2 in in-site degrees, being all the subjects of the first semester. The current pandemic situation and the lockdowns in Spain began in March, so the teaching of the year 2019/2020 was developed according to 
the original modality and the teaching in the academic year 2020/2021 for the classroom subjects were developed in a model hybrid (on-site/online).

Table 1. Student Assessment.

\begin{tabular}{|c|c|c|c|c|c|}
\hline \multirow[b]{2}{*}{ Academic Course } & \multicolumn{2}{|c|}{ Professor 1} & \multicolumn{2}{|c|}{ Professor 2} & \multirow{2}{*}{$\begin{array}{c}\Delta \\
\text { Medio }\end{array}$} \\
\hline & $20 / 21$ & $19 / 20$ & $20 / 21$ & $19 / 20$ & \\
\hline \multicolumn{6}{|c|}{ Planning and Organizing the subject } \\
\hline Know the syllabus, competencies and skills & 4,4 & 3,4 & 4,9 & 3,5 & 1,2 \\
\hline Reporting evaluation criteria & 4,1 & 3,2 & 4,9 & 3,7 & 1,05 \\
\hline \multicolumn{6}{|c|}{ Compliance with formal obligations } \\
\hline Communication and tutorship & 4,2 & 3,4 & 4,9 & 4,2 & 1,5 \\
\hline Teacher availability & 4,3 & 3,2 & 4,8 & 4,2 & 0,85 \\
\hline $\begin{array}{l}\text { Adjust teaching activities to specific goals, } \\
\text { content and methodologies }\end{array}$ & 4,3 & 3,3 & 4,8 & 3,8 & 1,0 \\
\hline Adjusted assessment & 4,3 & 3,3 & 4,9 & 3,8 & 1,05 \\
\hline \multicolumn{6}{|c|}{ Teaching methodology } \\
\hline $\begin{array}{l}\text { Clears up doubts adequately about the proposed } \\
\text { activities }\end{array}$ & 4,2 & 3,1 & 4,7 & 4,2 & 0,8 \\
\hline Use material that makes learning easier & 4 & 3,2 & 4,9 & 4,2 & 0,75 \\
\hline $\begin{array}{l}\text { The development of the subject allows a proper } \\
\text { follow-up and learning }\end{array}$ & 4,1 & 2,9 & 4,9 & 3,8 & 1,15 \\
\hline OVERALL RATING & 4,2 & 3,1 & 4,8 & 4,0 & 0,95 \\
\hline
\end{tabular}

Source: own elaboration

The results of the comparative analysis indicate an incremental improvement in all the items around one point, being in the case of the in-site modality (reflected in teacher 2) even greater. These results not only indicate the adequacy of the methodology to student learning, but also value its implementation in the current pandemic situation. The methodological change developed by innovation of the teaching team also allows us to affirm that the change in the teaching approach for an adaptation of the teaching has had greater effects in the in-site modality than in the online modality.

\subsection{Conclusions}

In conclusion, we can establish that once the model is implemented in the educational service, students get involved in real projects that provide them new social, professional and personal 
skills. In this way, student teams practice active listening, respect, sincerity, analytical, critical and communication skills. Orienting teams of students to a specific goal through a quality final project, activates their motivation to learn and move forward with the syllabus in order to apply the knowledges in each Sprint developing high-value Increments. Besides to acquiring learnings in a dynamic and practical way, they do it more quickly and efficiently, therefore, the academic results are better.

In a nutshell, the teaching model based on business agility for the development of products and services is applicable to the educational context, enabling the necessary change and transformation driven by the current era of pandemic in which we have had to reinvent teaching to new contexts and collaborative and remote work methodologies.

The results obtained allow us to conclude that the application of Scrum in the non-software educational field is adequate, substantially increasing the learning results of the students and the assessment of teaching both online and in-site, but having a greater effect in the case of adapting teaching to the hybrid model in a pandemic situation.

\section{References}

Cathcart, A.; Greer, D.; Neale, L.(2014) Learner-focused evaluation cycles: Facilitating learning using feedforward, concurrent and feedback evaluation. Assess. Eval. High. Educ. 39, 790-802.

Krehbiel, T.; Salzarulo, P.; Cosmah, M.; Forren, J.; Gannod, G.; Havelka, D.; Hulshult, A.; Merhout, J. (2017). Agile Manifesto for Teaching and Learning. J. Eff. Teach, 17, 90111.

Lembo, D., \& Vacca, M. (2012). Project Based Learning + Agile Instructional Design $=$ EXtreme Programming based Instructional Design Methodology for Collaborative Teaching (No. 8). Dipartimento di Informatica e Sistemistica "Antonio Ruberti”, Sapienza Università di Roma.

Lopez-Alcarria, A., Olivares-Vicente, A. \& Poza-Vilches, F. (2019). A Systematic Review of the Use of Agile Methodologies in Education to Foster Sustainability Competencies. Sustainability, 11 (2915), 1-29. doi:10.3390/su11102915.

Salza, P., Musmarra, P., \& Ferrucci, F. (2019). Agile methodologies in education: A review. Agile and lean concepts for teaching and learning, 25-45.

Stewart, J.C.; DeCusatis, C.S.; Kidder, K.; Massi, J.R. \& Anne, K.M.(2009). Evaluating Agile Principles in Active and Cooperative Learning. In Proceedings of the StudentFaculty Research Day, CSIS; Pace University: New York, NY, USA. 